Published in final edited form as:

J Cardiovasc Electrophysiol. 2004 August ; 15(8): 942-944.

\title{
The Link Between Hypothermia and the Brugada Syndrome
}

\author{
Jeffrey M. Fish, DVM and Charles Antzelevitch, PhD \\ Masonic Medical Research Laboratory Utica, NY
}

Ventricular epicardial and $\mathrm{M}$ cell, but not endocardial cell, action potentials display a large phase 1, due to the presence of a prominent transient outward current $\left(\mathrm{I}_{\mathrm{to}}\right)$, giving rise to a spike and dome or notched configuration of the action potential. ${ }^{1}$ Regional differences in $\mathrm{I}_{\text {to }}$ have been demonstrated in canine, feline, rabbit, rat, mouse and human ventricular myocytes.(see 2 for references) Important differences also exist in the magnitude of $\mathrm{I}_{\text {to }}$ and action potential notch between right and left ventricular epicardial and $\mathrm{M}$ cells with right ventricular cells displaying a much greater $\mathrm{I}_{\mathrm{to}} \cdot 3,4$

These transmural ion channel distinctions lead to a differential response of epicardium and endocardium to sodium channel block, ${ }^{5} \mathrm{I}_{\mathrm{KATP}}$ activation, ${ }^{6}$ and hypercalcemia. ${ }^{7}$ These conditions accentuate the epicardial action potential notch and can lead to loss of the action potential dome as a consequence of all-or-none repolarization at the end of phase 1.

Heterogeneous loss of the action potential dome within epicardium and between epicardium and endocardium, accentuates local epicardial as well as transmural dispersion of repolarization (TDR), thus creating a vulnerable window within epicardium as well as across the ventricular wall. Propagation of the epicardial action potential dome from regions where it is maintained to regions where it has been lost gives rise to phase 2 reentry, providing the trigger that captures the vulnerable window created by the increase in dispersion.

The electrocardiographic $\mathrm{J}$ wave, or Osborn wave, has long been recognized as pathognomonic of hypothermia ${ }^{8-12}$ and hypercalcemia. ${ }^{13-15}$ Studies involving the canine arterially perfused wedge preparation demonstrated that transmural voltage gradients due to differences in the early phases of repolarization of epicardium and endocardium are responsible for the manifestation of the electrocardiographic J wave. ${ }^{16}$ Decreasing the temperature of the coronary perfusate has been shown to accentuate this transmural voltage gradient by augmenting the action potential notch in epicardium but not endocardium, thus increasing the amplitude of the $\mathbf{J}$ wave. The ionic basis for the accentuation of the epicardial action potential notch was proposed to be due to differences in the $\mathrm{Q}_{10}$ for the kinetics of $\mathrm{I}_{\mathrm{Ca}}$ and $\mathrm{I}_{\mathrm{to}}$. This distinction would be expected to cause a greater cooling-induced slowing of $\mathrm{I}_{\mathrm{Ca}}$ activation than of $\mathrm{I}_{\text {to }}$ activation leading to a very significant outward shift in the balance of current during the early phases of the action potential.

Heterogeneous loss of the action potential dome can give rise to phase 2 reentry and VT under hypothermic conditions. Figure 1 illustrates an example of this phenomenon in the canine arterially-perfused right ventricular wedge preparation. Shown are action potentials simultaneously recorded from an endocardial and two epicardial sites, together with a pseudoECG. With a coronary perfusate temperature of $37^{\circ} \mathrm{C}$, the presence of a notch in the epicardial, but not endocardial action potential gives rise to a transmural voltage gradient that inscribes the $\mathrm{J}$ wave in the ECG. When the perfusate temperature is reduced to $29^{\circ} \mathrm{C}$, phase 1 of the

\footnotetext{
Address for correspondence: Dr. Charles Antzelevitch, Gordon K. Moe Scholar, Masonic Medical Research Laboratory, 2150 Bleecker Street, Utica, NY 13501-1787, Phone: 315-735-2217, Fax: 315-735-5648, E-mail: ca@mmrl.edu.

Supported by grant HL47678 from NHLBI (CA) and grants from the American Heart Association (JF, CA) and NYS and Florida Grand Lodges F. \& A.M.
} 
action potential notch is markedly accentuated, leading to accentuation of the notch in Epi2 and loss of the action potential dome in Epil. The augmented transmural voltage gradient is responsible for the accentuation of the J wave or ST segment elevation. Propagation of the dome from Epi2 to Epi1 results in a closely coupled phase 2 reentrant extrasystole that precipitates a short run of VT.

In 1992, Brugada and Brugada described a distinct electrocardiographic syndrome characterized by ST segment elevation in the right precordial leads and a right bundle branch block configuration of the ECG and a high incidence of sudden cardiac death, known today as the Brugada syndrome. ${ }^{17}$ Over 60 SCN5A mutations have been linked to the Brugada syndrome. The syndrome is inherited with an autosomal dominant mode of transmission and shows incomplete penetrance. Experimental models of the Brugada syndrome have been developed in the arterially perfused canine right ventricular wedge preparation using $\mathrm{I}_{\mathrm{K}-\mathrm{ATP}}$ activation or inhibition of $\mathrm{I}_{\mathrm{Na}}$ and $\mathrm{I}_{\mathrm{Ca}} \cdot 18,19$ As in the example of hypothermia illustrated in Figure 1, these conditions lead to heterogeneous all or none repolarization at the end of epicardial action potential phase 1 , resulting in a markedly abbreviated response in some areas of the epicardium compared to endocardium. The voltage gradient generated gives rise to an ST segment elevation and phase 2 reentry within the epicardium provides the trigger for the lethal arrhythmias. Agents that block $\mathrm{I}_{\text {to }}$ such as 4-aminopyridine or quinidine restore the epicardial action potential dome and normalize the ST segment.

Both experimental and clinical studies have provided support for this hypothesis. Quinidine has been shown to be effective in normalizing the ST segment and in the management of patients with the Brugada syndrome. ${ }^{20-22}$ Kurita and colleagues recorded monophasic action potentials from the epicardium of the right ventricular outflow tract of 3 Brugada syndrome patients and found a spike and dome morphology as predicted from the wedge models. ${ }^{23}$, ${ }^{24}$ A lower density of in $\mathrm{I}_{\mathrm{to}}$ in the hearts of females was recently shown to protect female hearts from developing phase 2 reentry. 25 This correlates with the phenotypic distribution of Brugada syndrome, which is 8 to 10 times more likely to develop in males despite equal transmission of the mutation to both sexes. The demonstration of a more prominent $\mathrm{I}_{\text {to }}$ in $\mathrm{RV}$ epicardium ${ }^{3}$, 25 also explains why the Brugada syndrome is a right ventricular disease.

In this issue of the Journal of Cardiovascular Electrophysiology, Nishida and coworkers 26 describe an interesting canine in vivo model of the Brugada syndrome induced by cooling the epicardium of the right ventricular outflow tract (RVOT) to $29^{\circ} \mathrm{C}$. The result is QT prolongation in the right precordial leads, a notched appearance of an MAP recorded from the epicardial surface of the RVOT, an increase in transmural dispersion, and vulnerability to induction of arrhythmias.

The model thus mimics some of the electrocardiographic and arrhythmic manifestations of the Brugada syndrome and provides support for the cellular mechanisms previously proposed to underlie the syndrome. The model is amenable for the study of a number of issues related to Brugada-like syndromes ranging from the nature of ST segment elevation to the mechanism responsible for VT. To what extent it may be useful for the assessment of a pharmacologic approach to therapy is not clear.

While the mechanism involved in the generation of the hypothermia-induced Brugada-like state may be similar to that contributing to the manifestation of the clinical syndrome, the difference between this acquired vs. congenital forms of the syndrome need to be appreciated and the limitations of the model recognized. For example, the kinetics of $\mathrm{I}_{\text {to }}$ reactivation would be expected to slow considerably at the cooler temperature leading to an exaggerated ratedependence and altered response to pharmacologic agents. The temperature gradient engendered by cooling the epicardial surface of the RVOT creates an exaggerated transmural 
dispersion similar to that seen under long QT conditions. An accentuated TDR may thus arise independently of the loss of the action potential dome, permitting the induction of Torsade de Pointes arrhythmias typically associated with long QT conditions rather than the rapid polymorphic VT that commonly attends the Brugada syndrome. As such, this in vivo model is also one of long QT and TdP arising in the right ventricle. In this respect, it differs from most acquired and congenital forms of the long QT syndrome, in which the principal substrate generally develops in the left ventricle or septum. The unusually fast heart rate in the model described by Nishida et al., presumably due to the anesthesia and isolation and ligation of the right cervical vagal nerve, may be another confounding factor in assessing electrophysiological and pharmacological mechanisms.

\section{References}

1. Litovsky SH, Antzelevitch C. Transient outward current prominent in canine ventricular epicardium but not endocardium. Circ Res 1988;62:116-126. [PubMed: 2826039]

2. Antzelevitch C, Dumaine R. Electrical heterogeneity in the heart: Physiological, pharmacological and clinical implications. In: Handbook of Physiology. Section 2 The Cardiovascular System. Page E, Fozzard HA, Solaro RJ, eds. 2001. Oxford University Press, New York.

3. Di Diego JM, Sun ZQ, Antzelevitch C. $\mathrm{I}_{\text {to }}$ and action potential notch are smaller in left vs. right canine ventricular epicardium. Am J Physiol 1996;271:H548-H561. [PubMed: 8770096]

4. Volders PG, Sipido KR, Carmeliet E, Spatjens RL, Wellens HJ, Vos MA. Repolarizing K+ currents ITO1 and IKs are larger in right than left canine ventricular midmyocardium. Circulation 1999;99:206210. [PubMed: 9892584]

5. Krishnan SC, Antzelevitch C. Sodium channel block produces opposite electrophysiological effects in canine ventricular epicardium and endocardium. Circ Res 1991;69:277-291. [PubMed: 1650294]

6. Di Diego JM, Antzelevitch C. Pinacidil-induced electrical heterogeneity and extrasystolic activity in canine ventricular tissues. Does activation of ATP-regulated potassium current promote phase 2 reentry? Circulation 1993;88:1177-1189. [PubMed: 7689041]

7. Di Diego JM, Antzelevitch C. High $\left[\mathrm{Ca}^{2+}\right]$-induced electrical heterogeneity and extrasystolic activity in isolated canine ventricular epicardium. Phase 2 reentry. Circulation 1994;89:1839-1850. [PubMed: 7511994]

8. Osborn JJ. Experimental hypothermia: respiratory and blood $\mathrm{pH}$ changes in relation to cardiac function. Am J Physiol 1953;175:389-398. [PubMed: 13114420]

9. Gussak I, Bjerregaard P, Egan TM, Chaitman BR. ECG phenomenon called the J wave. History, pathophysiology, and clinical significance. J Electrocardiol 1995;28:49-58. [PubMed: 7897337]

10. Anguera I, Valls V. Images in cardiovascular medicine. Giant $\mathbf{J}$ waves in hypothermia. Circulation 2000;101:1627-1628. [PubMed: 10747359]

11. Alhaddad IA, Khalil M, Brown EJ Jr. Osborn waves of hypothermia. Circulation 2000;101:E233E244. [PubMed: 10869275]

12. Ansari E, Cook JR. Profound hypothermia mimicking a Brugada type ECG. J Electrocardiol 2003;36:257-260. [PubMed: 12942489]

13. Kraus F. Ueber die wirkung des kalziums auf den kreislauf. Dtsch Med Wochenschr 1920;46:201203.

14. Sridharan MR, Horan LG. Electrocardiographic J wave of hypercalcemia. Am J Cardiol 1984;54:672673. [PubMed: 6475794]

15. Topsakal R, Saglam H, Arinc H, Eryol NK, Cetin S. Electrocardiographic J wave as a result of hypercalcemia aggravated by thiazide diuretics in a case of primary hyperparathyroidism. Jpn Heart J 2003;44:1033-1037. [PubMed: 14711198]

16. Yan GX, Antzelevitch C. Cellular basis for the electrocardiographic J wave. Circulation 1996;93:372379. [PubMed: 8548912]

17. Brugada P, Brugada J. Right bundle branch block, persistent ST segment elevation and sudden cardiac death: a distinct clinical and electrocardiographic syndrome: a multicenter report. J Am Coll Cardiol 1992;20:1391-1396. [PubMed: 1309182] 
18. Yan GX, Antzelevitch C. Cellular basis for the Brugada Syndrome and other mechanisms of arrhythmogenesis associated with ST segment elevation. Circulation 1999;100:1660-1666. [PubMed: 10517739]

19. Fish JM, Antzelevitch C. Cellular and Ionic Basis for the Sex-related Difference in the Manifestation of the Brugada Syndrome and Progressive Conduction Disease Phenotypes. J Electrocardiol 2003;36:173-179. [PubMed: 14716629]

20. Alings M, Dekker L, Sadee A, Wilde A. Quinidine induced electrocardiographic normalization in two patients with Brugada syndrome. PACE 2001;24:1420-1422. [PubMed: 11584468]

21. Suzuki H, Torigoe K, Numata O, Yazaki S. Infant case with a malignant form of Brugada syndrome. J Cardiovasc Electrophysiol 2000;11:1277-1280. [PubMed: 11083249]

22. Belhassen B, Viskin S, Fish R, Glick A, Setbon I, Eldar M. Effects of electrophysiologic-guided therapy with Class IA antiarrhythmic drugs on the long-term outcome of patients with idiopathic ventricular fibrillation with or without the Brugada syndrome [see comments]. J Cardiovasc Electrophysiol 1999;10:1301-1312. [PubMed: 10515552]

23. Kurita T, Shimizu W, Inagaki M, Suyama K, Taguchi A, Satomi K, Aihara N, Kamakura S, Kobayashi J, Kosakai Y. The electrophysiologic mechanism of ST-segment elevation in Brugada syndrome. J Am Coll Cardiol 2002;40:330-334. [PubMed: 12106940]

24. Antzelevitch C, Brugada P, Brugada J, Brugada R, Towbin JA, Nademanee K. Brugada syndrome: 1992-2002. A historical perspective. J Am Coll Cardiol 2003;41:1665-1671. [PubMed: 12767644]

25. Di Diego JM, Cordeiro JM, Goodrow RJ, Fish JM, Zygmunt AC, Perez GJ, Scornik FS, Antzelevitch C. Ionic and cellular basis for the predominance of the Brugada syndrome phenotype in males. Circulation 2002;106:2004-2011. [PubMed: 12370227]

26. Nishida K, Fujiki A, Mizumaki K, Sakabe M, Sugao M, Tsuneda T, Inoue H. A canine model of Brugada syndrome using regional epicardial cooling of the right ventricular outflow tract. $J$ Cardiovasc Electrophysiol 2004; In Press. 
A $\quad 37^{\circ} \mathrm{C}$.
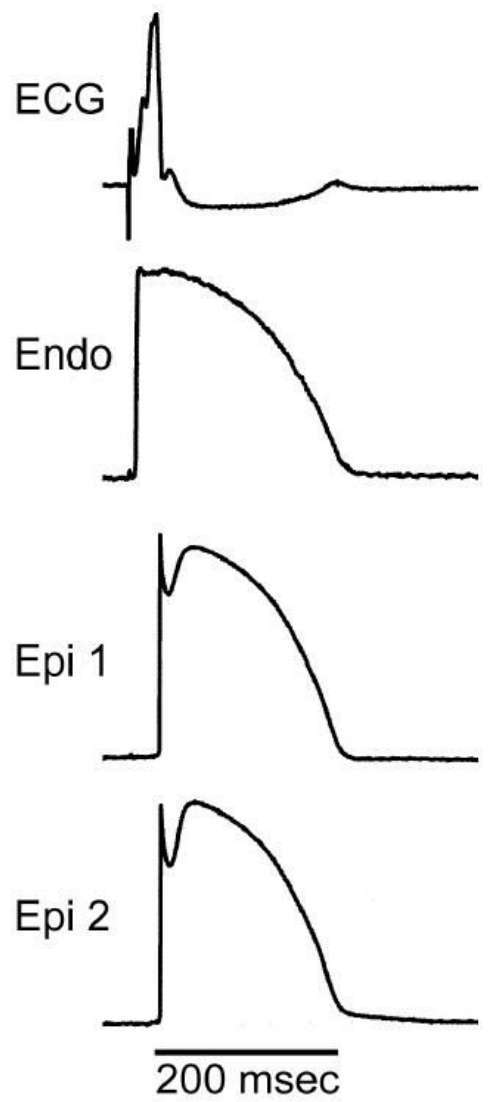

B $29^{\circ} \mathrm{C}$.
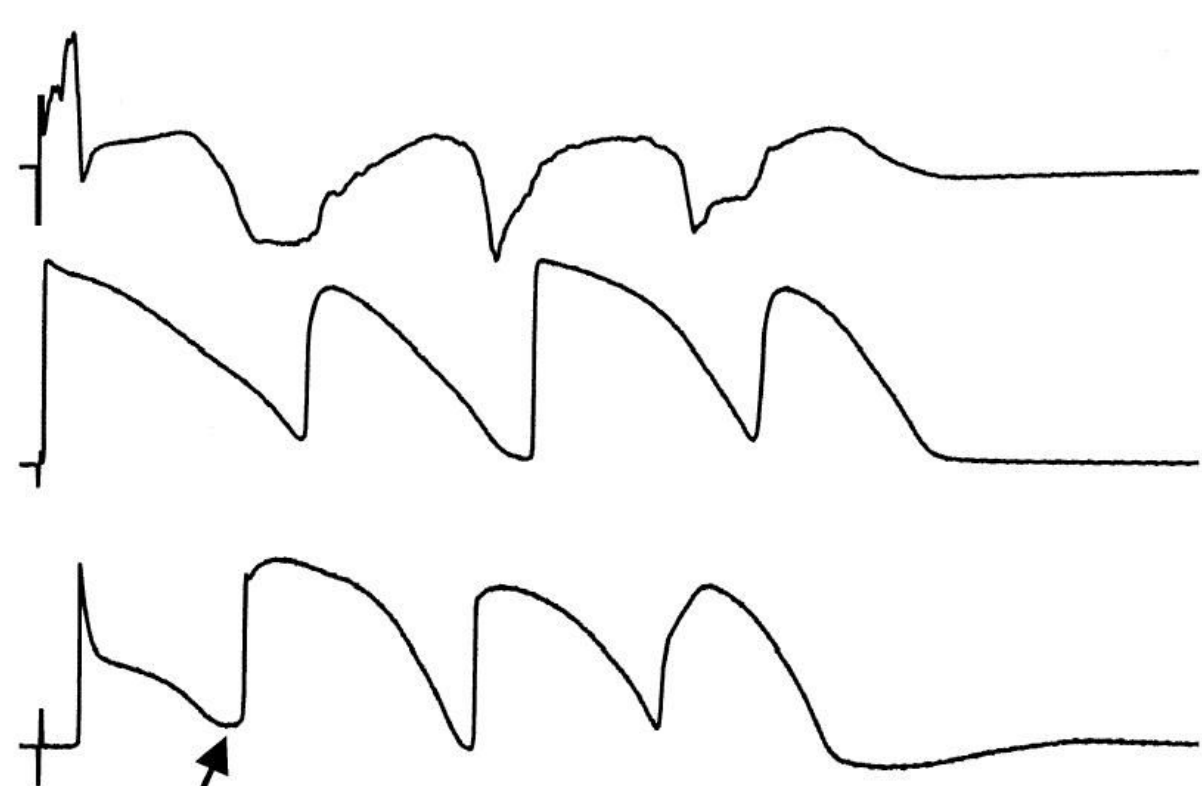

Figure 1.

Hypothermia-induced Brugada-like syndrome in the canine arterially-perfused right ventricular wedge preparation. Each panel shows transmembrane action potentials simultaneously recorded using floating glass microelectrodes from two epicardial and one endocardial site. A: Recorded with the temperature of the coronary perfusate at $37^{\circ} \mathrm{C}$. B: Recorded following cooling of the coronary perfusate to $29^{\circ} \mathrm{C}$. The cooler temperature enhances the epicardial action potential spike and dome morphology, leading to heterogeneous loss of the epicardial action potential dome, phase 2 reentry within the epicardium (arrow) and a short run of VT. BCL $=2000 \mathrm{~ms}$ 